\title{
Comparison of Different Thyroid Committed Doses in Radioiodine Therapy for Graves' Hyperthyroidism
}

\author{
Mariano Grosso, ${ }^{1}$ Antonio Traino, ${ }^{2}$ Giuseppe Boni, ${ }^{1}$ Elena Banti, ${ }^{1}$ Mauro Della Porta, ${ }^{1}$ \\ Gianpiero Manca, ${ }^{1}$ Duccio Volterrani, ${ }^{1}$ Serena Chiacchio, ${ }^{1}$ Abedallatif AlSharif, ${ }^{1}$ Elisa Borsò, ${ }^{1}$ \\ Rosanna Raschillà, ${ }^{1}$ Fabio Di Martino, ${ }^{2}$ and Giuliano Mariani ${ }^{1}$ \\ ${ }^{1}$ Regional Center of Nuclear Medicine, University of Pisa Medical School, Pisa, Italy \\ ${ }^{2}$ Health Physics Unit, Section of Medical Physics, University Hospital, Pisa, Italy
}

\begin{abstract}
Despite vast worldwide experience in the use of ${ }^{131}$ I for treating Graves' disease (GD), no consensus of opinion exists concerning the optimal method of dose calculation. In one of the most popular equations, the administered ${ }^{131}$ I dose is directly proportional to the estimated thyroid gland volume and inversely proportional to the measured 24-hour radioiodine uptake. In this study, we compared the efficiency of different tissue-absorbed doses to induce euthyroidism or hypothyroidism within 1 year after radioiodine therapy in GD patients. The study was carried out in 134 GD patients (age, $53 \pm 14$ year; range, 16-82 year; thyroid volume, $28 \pm 18 \mathrm{~mL}$; range, 6-95 $\mathrm{mL}$; average 24-hour thyroid uptake, $72 \%$ ) treated with ${ }^{131}$ I therapy. The average radioiodine activity administered to patients was $518 \pm 226 \mathrm{MBq}$ (range, 111-1110). The corresponding average thyroid absorbed dose, calculated by a modified Medical Internal Radiation Dose (MIRD) equation was $376 \pm 258$ Gy (range, 99-1683). One year after treatment, 58 patients (43\%) were hypothyroid, 57 patients (43\%) were euthyroid, and 19 patients (14\%) remained hyperthyroid. The patients were divided into 3 groups: 150 Gy $(\mathrm{n}=32), 300 \mathrm{~Gy}(\mathrm{n}=58)$ and $>300 \mathrm{~Gy}$ $(\mathrm{n}=44)$. No significant difference in the rate of recurrent hyperthyroidism was found among the 3 groups (150 Gy: 15\%; $300 \mathrm{Gy:} \mathrm{14 \% ;} \mathrm{and} \mathrm{>300} \mathrm{Gy:} \mathrm{14 \% ;} \mathrm{chi-square} \mathrm{test,} \mathrm{p}=0.72$ ). Whereas, the rate of hypothyroidism in the 3 groups was significantly correlated with the dose (150 Gy: 30\%; 300 Gy: 46\%; $>300 \mathrm{Gy:}$ 71\%; chi-square test, $\mathrm{p}=0.0003)$. The results obtained in this study show no correlation between dose and outcome of radioiodine therapy (in terms of persistent hyperthyroidism) for thyroid absorbed doses $\geq 150 \mathrm{~Gy}$, while confirming the relation between the thyroid absorbed dose and the incidence of hypothyroidism in GD patients.
\end{abstract}

Key words: Graves' disease, radioiodine therapy, clinical outcome, dosimetry

\section{INTRODUCTION}

Graves' disease (GD) is the most common cause of hyperthyroidism. Over the past 30 years, treat-

Address reprint requests to: Mariano Grosso; Regional Center of Nuclear Medicine, University of Pisa Medical School; Via Roma 67, I-56126 Pisa, Italy; Tel.: +39-050992115; Fax: +39-050-552100

E-mail: m.grosso@med.unipi.it ment of GD has most commonly been performed using 1 or more of 3 modalities: medical therapy, total thyroidectomy, and radioiodine therapy. ${ }^{1}$ All such treatments are effective, but opinions vary regarding their relative indications, as no single treatment guarantees permanent euthyroidism. ${ }^{2,3}$ Considerable disparity of opinion also exists among thyroid specialists around the world regarding the first-choice treatment for a "typical" GD patient. ${ }^{4-6}$ Radiodiodine is being in- 
creasingly used as first-line therapy for GD patients. It is the treatment of choice for relapsed GD in the United States, while in Europe and Japan it usually represents the second-line therapy.

The goal of treatment with radioiodine is to destroy sufficient thyroid tissue to cure hyperthyroidism by rendering the patient either euthyroid or hypothyroid. Although this treatment is highly effective, with a cure rate approaching $100 \%$ after 1 or more cycles, ${ }^{7}$ no consensus of opinion exists concerning the optimal method of calculating the thyroid absorbed dose (Gy) or of establishing the ${ }^{131}$ I activity $(\mathrm{MBq})$ to be administered. ${ }^{8}$

Therefore, debate is continuing in the scientific community as to the best way of estimating such parameters, either by fixed activity, fixed thyroid absorbed doses, and so forth. Several studies have attempted to determine the optimal dose or activity of radioiodine for curing hyperthyroidism while avoiding the development of permanent hypothyroidism. Regimens used have included low activities $(80 \mathrm{MBq}),{ }^{9,10}$ various fixed activities $(185,370$, and $555 \mathrm{MBq}),{ }^{11,12}$ and doses calculated on the basis of thyroid size, uptake of radioiodine, and turnover of ${ }^{131} \mathrm{I} .{ }^{13}$

In this study, we compared the efficacy of different tissue-absorbed doses to induce euthyroidism or hypothyroidism within 1 year after radioiodine therapy in an attempt to elucidate some of the stillopen issues in the continuing debate over treatment parameters and to further optimize radioiodine treatment for individual patients with GD.

\section{MATERIALS AND METHODS}

\section{Patients}

A total of 134 patients (102 women and 32 men, with a mean age of $53 \pm 14$ year; range, 16-82 year) were enrolled in this study comparing the clinical effectiveness of different thyroid-committed doses in radioiodine therapy. All patients included had proven thyrotoxicosis from GD, as confirmed by suppressed basal thyroid-stimulating hormone (TSH), increased serum tri-iodothyronine, and thyroxine serum levels and on the presence of TSH receptor antibodies and/or evidence of ophthalmopathy.

\section{Clinical Assessment}

Before ${ }^{131}$ I therapy, each patient underwent a full clinical evaluation, determination of thyroid vol- ume (by high-resolution ultrasound examination), serum analysis (TSH, fT4, fT3, and antithyroid autoantibodies including TSH-receptor antibodies), 4-hour and 24-hour radioiodine uptake, and a thyroid scan. Besides possible refusal of radioiodine therapy by the patient, exclusion criteria included an age younger than 18 years, suspicion of pregnancy, and the presence of any suspicious thyroid nodule on ultrasound examination. All patients were advised to stay on a generic, low-iodine diet for at least 2 weeks prior to measurements, and were taken off antithyroid drug therapy prior to radioiodine administration (average, 7.5 days; range, 5-30 days). Antithyroid drug treatment was restarted at least 7 days following ${ }^{131}$ I therapy.

\section{Assessment by Investigation \\ Radioiodine uptake (RAIU) and determination of ${ }^{131}$ I kinetics}

The RAIU and ${ }^{131} \mathrm{I}$ kinetics in the patients were evaluated as follows:

1. the radioactivity count rate from a diagnostic dose of ${ }^{131} \mathrm{I}(1.85 \mathrm{MBq})$ placed in a thyroid phantom was measured using a properly collimated and calibrated $\mathrm{NaI}(\mathrm{Tl})$ probe (reference measurement);

2. thyroid uptake at 4 hour and 24 hour postadministration of the diagnostic ${ }^{131} \mathrm{I}$ dose was measured in each patient in the upright position, with the anterior surface of the neck at $25 \mathrm{~cm}$ from the same $\mathrm{NaI}(\mathrm{Tl})$ probe $(120 \mathrm{sec}-$ ond counting time);

3. the patterns of ${ }^{131}$ I kinetics in the thyroid were identified after calculating the 4-hr $\left(\mathrm{U}_{4}\right)$ and the 24-hour $\left(\mathrm{U}_{24}\right)$ fractional thyroidal uptake, by deriving from such uptake values estimates of the half-time of ${ }^{131} \mathrm{I}$ in the thyroid ( $\mathrm{T}_{\text {eff }}$ ). Based on a priori assumptions derived from literature data for the expected $\mathrm{T}_{\text {eff }}$ values, $\mathrm{pa}-$ tients were divided into 4 subgroups:

- slow kinetics: $\mathrm{T}_{\text {eff }}=169$ hour; $\mathrm{T}_{\max }=4$ hour with $\mathrm{U}_{24} / \mathrm{U}_{4}>0.92$;

- normal kinetics: $\mathrm{T}_{\mathrm{eff}}=121$ hour; $\mathrm{T}_{\max }=24$ hour with $\mathrm{U}_{24} / \mathrm{U}_{4}>1$;

- normal kinetics with fast uptake: $\mathrm{T}_{\text {eff }}=121$ hour; $\mathrm{T}_{\max }=4$ hour with $\mathrm{U}_{24} / \mathrm{U}_{4}$ between $0.88-0.92$; and

- fast kinetics: $\mathrm{T}_{\mathrm{eff}}=107$ hour; $\mathrm{T}_{\max }=4$ hour with $\mathrm{U}_{24} / \mathrm{U}_{4}<0.88$,

were $\mathrm{T}_{\max }$ is the time at which fractional thyroidal uptake is maximum. 
This method for predicting activity and dose to the gland has some disadvantages because it does not accurately follow radioiodine kinetics in a patient's thyroid by sequential measurements (other than the 4-hour and 24-hour time points) during the uptake and clearance phase following tracer administration. Thus, the calculated predicted dose and activity are approximately $\pm 40 \%$, which is considered acceptably accurate for internal dosimetry estimates. On the other hand, this method has the advantage of being not timeconsuming, thus fitting very well with the scheduling requirements of a busy department of nuclear medicine.

\section{Thyroid ultrasound examination}

Ultrasound examination was performed using an AU-4 echograph (ESAOTE; Florence, Italy), equipped with an array $7.5-\mathrm{Hz}$ transducer, with all measurement being carried out by the same operator. Volume was determined by the ellipsoid model (length $\times$ width $\times$ depth $\times \pi / 6$ ) for each lobe and isthmus; thyroid mass was estimated assuming thyroid density being equal to 1 $\mathrm{g} / \mathrm{mL}$.

\section{Thyroid scintigraphy}

Twenty-four (24) hours after receiving the ${ }^{131} \mathrm{I}$ tracer dose $(1.85 \mathrm{MBq})$, all patients underwent ${ }^{131} \mathrm{I}$ scintigraphy immediately after performing the 24hour RAIU measurement before receiving the therapeutic dose, to confirm the GD diagnosis.

\section{Radioiodine therapy}

The following equation was used to calculate the required ${ }^{131}$ I activity to achieve the target dose:

$$
\begin{aligned}
& D_{T}=\frac{\Delta_{n p} U A_{0}}{m_{0}} \\
& \quad\left\{\frac{T_{\max }}{2}+\frac{1}{\gamma A_{0}}\left[1-\left(1-2 \gamma \frac{A_{0} T_{\text {eff }}}{\ln (2)}\right)^{\frac{1}{2}}\right]\right\}
\end{aligned}
$$

where $\Delta_{\mathrm{np}}=0.032 \mathrm{mGy} \times \mathrm{g} \times \mathrm{MBq}^{-1} \times \mathrm{s}^{-1}$ is the equilibrium dose constant for nonpenetrating radiations; ${ }^{14} \mathrm{~A}_{0}(\mathrm{MBq})$ is the ${ }^{131} \mathrm{I}$ activity administered to the patient; $T_{\text {eff }}$ (hour) is the effective half-life of radiodine in the thyroid; $\mathrm{U}=$ $\mathrm{A}_{\mathrm{m}} / \mathrm{A}_{0}$ is the fractional thyroidal uptake $\left(\mathrm{A}_{\mathrm{m}}\right.$ is the maximum activity in the gland expressed in $\mathrm{MBq}$ ); $\mathrm{T}_{\max }$ (hour) is the time to maximum uptake; $m_{0}(g)$ is the pretherapy mass of the gland; $\mathrm{U}$ is the maximum fractional thyroidal uptake (whether it is $\mathrm{U}_{4}$ or $\mathrm{U}_{24}$ ). Equation 1 is a predictive equation which allows for a calculation of the radiation dose to the thyroid, taking into account the change of thyroid mass during the clearance phase of ${ }^{131}$ I from the gland. ${ }^{15}$

Based on calculations obtained with Equation 1 , patients were retrospectively divided into 3 groups according to the absorbed target dose: group I included 32 patients $(24 \%)$ whose thyroid average absorbed dose was 150 Gy (148 \pm 26 Gy); group II included 58 patients (43\%) whose thyroid average absorbed dose was $300 \mathrm{~Gy}$ $(295 \pm 52 \mathrm{~Gy})$; and group III included 44 patients $(33 \%)$ whose thyroid average absorbed dose was greater than 300 Gy $(649 \pm 281 \mathrm{~Gy})$. The patients included in groups I and II were randomly chosen; the patients included in group III were treated before, by a fixed value of radioiodine activity (range, 470-586 MBq), based on our experience.

The average radioiodine activity administered to patients was $518 \pm 226 \mathrm{MBq}$, with a range of $111-1110(14 \pm 6.1 \mathrm{mCi}$; range, $3-30 \mathrm{mCi})$. The corresponding average thyroid absorbed dose, as calculated by the Medical Internal Radiation Dose (MIRD) equation (as modified by Traino et al. ${ }^{15}$ ), was $376 \pm 258$ Gy (range, 99-1683) (see Table 1).

\section{Follow-up}

The clinical outcome 1 year after ${ }^{131}$ I treatment was evaluated on the basis of a regular followup. Therapeutic success (i.e., elimination of hyperthyroidism demonstrated at the 1-year followup evaluation) resulted in either euthyroidism or hypothyroidism.

\section{RESULTS}

One year after ${ }^{131}$ I treatment, a euthyroid state was achieved in 57 patients $(43 \%)$ and a hypothyroid state in 58 patients (43\%), while 19 patients $(14 \%)$ remained hyperthyroid.

Of the 32 patients receiving an average thyroid tissue dose of $150 \mathrm{~Gy}, 27$ patients (85\%) had a favorable response to radioiodine therapy, with 19 patients $(60 \%)$ being euthyroid and 8 patients $(25 \%)$ being hypothyroid. The remaining 5 patients $(15 \%)$ had persistent hyperthyroidism.

Of the 58 patients receiving an average thyroid tissue dose of $300 \mathrm{~Gy}, 50$ patients showed a response to therapy, with 27 patients $(46 \%)$ being euthyroid and 23 patients (40\%) being hypothy- 


\begin{tabular}{|c|c|c|c|c|}
\hline & $150 G y$ & $300 \mathrm{~Gy}$ & $>300 \mathrm{~Gy}$ & Total \\
\hline Patients (no.) & 32 & 58 & 44 & 134 \\
\hline Age (years) & $61 \pm 13$ & $54 \pm 14$ & $48 \pm 15$ & $53 \pm 14$ \\
\hline Thyroid volume (mL) & $38 \pm 24$ & $26 \pm 14$ & $23 \pm 13$ & $28 \pm 18$ \\
\hline Radioiodine uptake (\%) & $56 \pm 22$ & $69 \pm 19$ & $74 \pm 20$ & $72 \pm 20$ \\
\hline Activity administered (MBq) & $455 \pm 250$ & $444 \pm 181$ & $663 \pm 193$ & $518 \pm 226$ \\
\hline
\end{tabular}

roid. The remaining 8 patients $(14 \%)$ had persistent hyperthyroidism.

In the group of 44 patients receiving an average thyroid tissue dose greater than $300 \mathrm{~Gy}, 27$ patients $(85 \%)$ responded favorably to therapy, with 11 patients (25\%) being euthyroid and 27 patients $(61 \%)$ being hypothyroid. The remaining 6 patients (14\%) remained hyperthyroid (see Fig. 1).

No significant difference in the rate of persisting or recurrent hyperthyroidism was found among the three groups (group I, 15\%; group II, $14 \%$, and group III, $14 \%$; chi-square test, $p=$ 0.72). On the other hand, a significant difference in the rate of hypothyroidism was found between the cured (euthyroid or hypothyroid) patients of the 3 groups (150 Gy, 30\%; $300 \mathrm{~Gy}, 46 \%$; >300 Gy, $71 \%$; chi-square test, $p=0.0003$ ).

When analyzing other factors which might further affect therapeutic outcome, no statistically significant correlation was found between baseline thyroid volume and outcome (average thy- roid volume in persisting or recurrent hyperthyroid patients was $27 \pm 14 \mathrm{~mL}$; range, $10-52 \mathrm{~mL}$ versus $28 \pm 18 \mathrm{~mL}$ in hypothyroid and euthyroid patients; range, $6-95 \mathrm{~mL}$; $t$ test, $p=0.78$ ).

Similarly, no statistically significant correlation was found between maximum thyroid uptake and outcome (average thyroid uptake in persisting or recurrent hyperthyroid patients was $72 \% \pm$ $23 \%$, versus $67 \% \pm 21 \%$ in hypothyroid and euthyroid patients; $t$ test, $p=0.45$ ).

Finally, no statistically significant correlation was found between age and outcome (average age in persisting or recurrent hyperthyroid patients was $48 \pm 12$ years; range, $21-68$ years versus $54 \pm 15$ years; range, 16-82 years) in hypothyroid and euthyroid patients ( $t$ test, $p=0.07$ ) (Table 2).

\section{DISCUSSION}

Radioiodine therapy is a well-established treatment for Graves' hyperthyroidism. The use of ra-

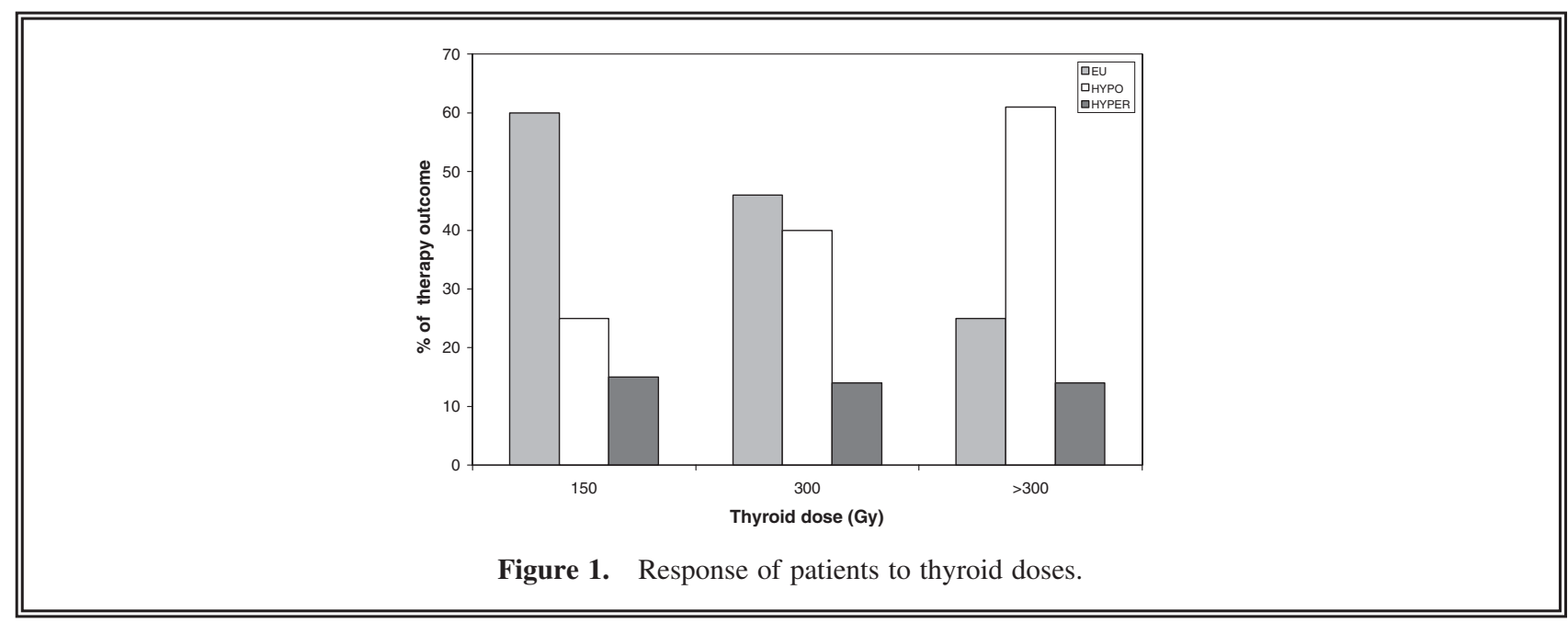




\begin{tabular}{||lcccc||}
\hline Table 2. Final Outcome 12 Months After Radioiodine Therapy in 134 GD Patients According to Intended Target Doses \\
\hline Patients $(n)$ & $150 G y$ & $300 G y$ & $>300$ Gy & Total \\
Hypothyroidism (\%) & 32 & 58 & 44 & 134 \\
Euthyroidism (\%) & $25 \%$ & $40 \%$ & $61 \%$ & $43 \%$ \\
Hyperthyroidism (\%) & $60 \%$ & $46 \%$ & $25 \%$ & $14 \%$ \\
Thyroid dose (Gy) & $15 \%$ & $14 \%$ & $649 \pm 281$ & $376 \pm 258$ \\
\hline GD, Graves' disease; Gy, absorbed dose. & $148 \pm 26$ & & \\
\hline
\end{tabular}

dioiodine in hyperthyroidism is increasing, particularly as first-line therapy for GD patients in whom the likelihood of success with antithyroid drugs is limited. Especially in the United States, young adult patients are now offered radioiodine earlier in the course of their disease, ${ }^{16}$ because onset of GD at a young age has been reported to be associated with an increased likelihood of relapse after medical treatment alone. ${ }^{17,18}$

Despite widespread use of ${ }^{131}$ I therapy for GD patients, no consensus of opinion exists concerning the optimal method of dose calculation. This is owing to several factors, including varying goals of treatment (hypothyroidism versus euthyroidism), and the lack of comprehensive studies relating the efficacy of different treatment protocols to outcomes. ${ }^{8}$ Because of the excellent clinical results achieved with levothyroxine replacement therapy, hypothyroidism following ${ }^{131}$ I therapy is not considered a complication by the majority of nuclear medicine and endocrinology specialists. Thus, therapy outcome is considered to be favorable also for the patients reaching permanent hypothyroidism after ${ }^{131} \mathrm{I}$ therapy.

Several factors have been considered to influence the outcome of radioiodine treatment. Many studies have demonstrated that patients with larger-volume thyroid glands ${ }^{10}$ and severe hyperthyroidism are more likely to fail to respond to a single dose of radioiodine. In our series, all the 9 patients with a thyroid volume of more than $60 \mathrm{~mL}$ responded favorably to radioiodine therapy ( 3 patients became hypothyroid and 6 patients became euthyroid). Treatment with antithyroid drugs has been reported to confer a certain degree of radioresistance, although with conflicting reports (some studies showing an effect only with propylthiouracil alone).

Given the need to prevent persistent hyperthyroidism and the high likelihood of possible hypothyroidism after any protocol of ${ }^{131} \mathrm{I}$ ther- apy, ${ }^{19,20}$ ablative radioiodine therapy with a 300 Gy absorbed dose is considered to be an effective treatment of hyperthyroidism in GD patients. $^{21}$

In this study, we have compared the outcome of treatment with 3 calculated dose regimens of radioiodine (150 Gy, $300 \mathrm{~Gy}$, and $>300 \mathrm{~Gy}$ ) in patients with GD. The percentage of hypothyroid patients 1 year after ${ }^{131}$ I therapy administration increased with the thyroid absorbed dose (Fig. 1): $25 \%$ in group I (150 Gy), $40 \%$ in group II (300 Gy), and $61 \%$ in group III (>300 Gy), while the percentage of hyperthyroid patients $(\sim 15 \%)$ was similar in 3 groups. This means that the favorable response (percentage of euthyroid and hypothyroid patients) to ${ }^{131}$ I therapy was relatively independent from the actual thyroid-committed doses. Consistent with prior reports, our results confirm the efficacy of radioiodine therapy in $85 \%$ of the patients treated at the 1-year followup evaluation. ${ }^{22}$

\section{CONCLUSIONS}

In conclusion, our experience suggests no correlation between the thyroid-committed dose and the outcome of radioiodine therapy for thyroid absorbed doses $\geq 150$ Gy in GD patients, while confirming the relationship between the thyroid absorbed dose and the incidence of hypothyroidism. Thus, it seems to confirm that:

- It is not useful for the thyroid to absorb a dose over $150 \mathrm{~Gy}$, except in the case of ophthalmopathy and high immunity.

- It is important to perform a personal dosimetry, to avoid giving activities too high.

- A fixed-activity administration is a convenient and cost-effective method but not patient-specific, and the results cannot be predicted unless a very high amount of activity is administered; 
but, in that case, the therapy is not optimized with respect to radiation safety (ALARA principle).

We are currently assessing the possible relation between the outcome of radioiodine therapy in GD and the reduction of thyroid volume as a consequence of such therapy. This is to optimize the individual calculation of ${ }^{131} \mathrm{I}$ activity to administer to the patient.

\section{REFERENCES}

1. Torring O, Tallstedt L, Wallin G, et al. Graves' hyperthyroidism: Treatment with antithyroid drugs, surgery, or radioiodine - a prospective, randomized study. Thyroid Study Group. J Clin Endocrinol Metab 1996;81: 2986.

2. Glinoer D, Hesch D, Lagasse R, et al. The management of hyperthyroidism due to Graves' disease in Europe in 1986: Results of an international survey. Acta Endocrinol Suppl (Copenh) 1987;285:3.

3. Solomon B, Glinoer D, Lagasse R, et al. Current trends in the management of Graves' disease. J Clin Endocrinol Metab 1990;70:1518.

4. Wartofsky L, Glinoer D, Solomon B, et al. Differences and similarities in the diagnosis and treatment of Graves' disease in Europe, Japan, and the United States. Thyroid 1991;1:129.

5. Ford HC, Delahunt JW, Feek CM. The management of Graves' disease in New Zealand: Results of a national survey. NZ Med J 1991;104:251.

6. Nagayama Y, Izumi M, Nagataki S. The management of hyperthyroidism due to Graves' disease in Japan in 1988: The Japan Thyroid Association. Endocrinol Jpn 1989;36:299.

7. Franklyn JA, Daykin J, Drolc Z, et al. Long-term follow-up of treatment of thyrotoxicosis by three different methods. Clin Endocrinol (Oxf) 1991;34:71.

8. Shapiro B. Optimization of radioiodine therapy of thyrotoxicosis: What have we learned after 50 years? $J$ Nucl Med 1993;34:1638.
9. Lowdell CP, Dobbs HJ, Spathis GS, et al. Low-dose ${ }^{131} \mathrm{I}$ in treatment of Graves' disease. JR Soc Med 1985;78:197.

10. Nordyke RA, Gilbert FI, Jr. Optimal iodine-131 dose for eliminating hyperthyroidism in Graves' disease. $J$ Nucl Med 1991;32:411.

11. Watson AB, Brownlie BE, Frampton CM, et al. Outcome following standardized $185 \mathrm{MBq}$ dose ${ }^{131} \mathrm{I}$ therapy for Graves' disease. Clin Endocrinol (Oxf) 1988;28:487.

12. Jarlov AE, Hegedus L, Kristensen LO, et al. Is calculation of the dose in radioiodine therapy of hyperthyroidism worthwhile? Clin Endocrinol (Oxf) 1995;43:325.

13. Sridama V, McCormick M, Kaplan EL, et al. Long-term follow-up study of compensated low-dose ${ }^{131}$ I therapy for Graves' disease. N Engl J Med 1984;311:426.

14. Stabin MG. Internal radiation dosimetry. In: Henkin RE et al., eds., Nuclear Medicine Vol. I. St. Louis: Mosby, 1996;316.

15. Traino AC, Di Martino F, Lazzeri M. A dosimetric approach to patient-specific radioiodine treatment of Graves' disease with incorporation of treatment induced changes in thyroid mass. Med Phys 2004;31:2121.

16. Hennemann G, Krenning EP, Sankaranarayanan K. Place of radioactive iodine in treatment of thyrotoxicosis. Lancet 1986;1:1369.

17. Yamada T, Aizawa T, Koizumi Y, et al. Age-related therapeutic response to antithyroid drug in patients with hyperthyroid Graves' disease. J Am Geriatr Soc 1994;42:513.

18. Allahabadia A, Daykin J, Holder RL, et al. Age and gender predict the outcome of treatment for Graves' hyperthyroidism. J Clin Endocrinol Metab 2000;85:1038.

19. Graham GD, Burman KDN. Radioiodine treatment of Graves' disease. An assessment of its potential risks. Ann Intern Med 1986;105:900.

20. Cunnien AJ, Hay ID, Gorman CA, et al. Radioiodineinduced hypothyroidism in Graves' disease: Factors associated. J Nucl Med 1982;23:978.

21. Willemsen UF, Knesewitsch P, Kreisig T, et al. Functional results of radioiodine therapy with a 300-Gy absorbed dose in Graves' disease. Eur J Nucl Med 1993;20:1051.

22. Alexander Ek, Larsen PR. High-dose ${ }^{131}$ I therapy for the treatment of hyperthyroidism caused by Graves' disease. J Clin Endocrinol Metabol 2002;87:1073. 